\title{
Teenage risky behavior and parental supervision: the unintended consequences of multiple shifts school systems
}

\author{
Ana Reynoso ${ }^{1}$ and Martín A. Rossi ${ }^{2}$ \\ ${ }^{1}$ Department of Economics \\ Yale University \& University of Michigan \\ 611 Tappan Av., Ann Arbor, MI 48109, areynoso@umich.edu \\ ${ }^{2}$ Department of Economics \\ Universidad de San Andrés \\ Vito Dumas 284, B1644BID Victoria, Buenos Aires, Argentina, +54 1147256948 , \\ mrossi@udesa.edu.ar.
}

We thank Joseph Altonji, Juan Carlos Hallak, Dean Karlan, Costas Meghir, Jonah Rockoff, Chris Udry, anonymous referees, and various participants to presentations at Universidad de La Plata, University of Miami, Universidad de San Andrés, Asociación Argentina de Economía Política (AAEP), InterAmerican Development Bank, and Latin American and Caribean Economic Association (LACEA) meeting for useful comments and suggestions. We acknowledge the invaluable help from the authorities of Escuela Superior de Comercio Carlos Pellegrini. Lucía Rodríguez Pardina, María Amelia Gibbons, and Nicolás Roig provided excellent research assistance. All errors are ours.

\begin{abstract}
We study the relationship between attending high school at night and the probability of engaging in risky behavior, such as having unsafe sex or consuming substances. To address potential endogeneity concerns we take advantage of a random assignment of high school students to daytime and night shifts in the city of Buenos Aires. Using an original survey on students attending their last year of high school, we find that girls attending high school in the evening start having sex at an earlier age and present a higher probability of getting an abortion. We find no significant differences for substance use. Our experimental approach suggests that the link between high school shift and risky behavior is causal. Results hold when we use an alternative sample of alumni. Finally, we report evidence that the lack of parental supervision is the mechanism underlying our results.
\end{abstract}

\section{Introduction}

The initiation in activities related to risky behavior such as having unsafe sex or consuming substances is, typically, an adolescent phenomenon. Wellings et al. (2006) document that the median age at first intercourse is below 19 in most countries in the world and the National Center on Addiction and Substance Abuse (hereafter CASA) at Columbia University reports

This is the author manuscript accepted for publication and has undergone full peer review but has not been through the copyediting, typesetting, pagination and proofreading process, which may lead to differences between this version and the Version of Record. Please cite this article as doi: $10.1111 /$ ecin.12759

This article is protected by copyright. All rights reserved. 
that initiation in consumption of alcohol and drugs occurs almost certainly before the age of 21 (CASA, 2005). Understanding the choice of timing and the conditions under which adolescents initiate risky activities is important given their long lasting health and social consequences. Many studies have shown that the first intercourse experience entails permanent emotional consequences and determines future sexual behavior, especially for girls (see Livingston et al. (2015) for a review of salient papers). Other studies have shown that adolescents that start having sex earlier take more sexual risks such as having intercourse under the effects of drugs (Livingston et al., 2015) and are more likely to develop cervix cancer (Louie et al., 2009) than their peers that initiate intercourse after the age of 16. Given that adolescence is the second time (after early childhood) in the lifetime of an individual when policy interventions can really make a change (Conti \& Heckman, 2014), the study of the determinants of entry into risky behavior is a high research priority that should pay particular attention to policies affecting youths' environments. One such policy is mandated high school schedules. In this paper we use experimental variation in the time of the day adolescents start high school classes to estimate the impact of going to school at night on the probability of getting an unlawful abortion, the age of intercourse initiation, and the probability of using illegal substances.

The offer of night high school for adolescents, though still modest, has been growing, especially in developing countries where multiple shifts school systems are used to increase the supply of education while overcoming infrastructure constraints. ${ }^{1}$ In Argentina, the two most prestigious and biggest public high schools in Buenos Aires offer courses in the evening session in addition to two daytime sessions to accommodate the great demand for slots in these schools. ${ }^{2}$ Similarly important and highly demanded public high schools in Paraguay also offer night and daytime shifts. ${ }^{3}$ Furthermore, many countries in the region offer night high school in the context of programs to extend high school education opportunities to adolescents that dropped out from high school, typically to take jobs in daytime hours. ${ }^{4}$. In

\footnotetext{
${ }^{1}$ In this paper, when we use the terms night high school or evening high school we refer to high school programs offered to adolescents in the evening shift, as opposed to adult school that usually takes place in the night hours.

${ }^{2}$ These high schools are Escuela Superior de Comercio Carlos Pellegrini and Colegio Nacional Buenos Aires. They are considered high quality schools because they depend upon the University of Buenos Aires. Each of these schools admit around 400 students every year, which is more than five times the average amount of incoming students among all high schools in the city of Buenos Aires.

3 Examples of these schools include the prestigious Colegio Nacional de la Capital General Bernardino Caballero in the city of Asusnción and Colegio Nacional de EMD Don Rigoberto Caballero in the city of San Ignacio.

${ }^{4}$ In Argentina, these programs have been implemented in the city of Buenos Aires, the Great Buenos Aires area, and the province of Córdoba (Llorente (2014) and Terigi (2012)). Other countries in Latin America that implement these policies include Brazil, Chile, Ecuador, Honduras, Jamaica, Mexico, and Trinidad y Tobago (Jáuregui et al., 2003)
} 
this paper we provide the first evaluation of the impact of going to school at night on adolescent behavior.

In our empirical strategy we take advantage of a random assignment of high school students to daytime and night shifts in one of the biggest high schools in Argentina. The public high school Escuela Superior de Comercio Carlos Pellegrini in the city of Buenos Aires assigns high school students to morning, afternoon, and night shifts through a public lottery, thus generating an exogenous variation in the time students go to high school. We conduct an original survey of the universe of the 2013 graduating cohort and a sample of alumni of this high school to estimate the relationship between going to school at night and risky behavior. The outcomes of interest are abortion (an illegal practice in Argentina) for girls, early intercourse initiation for girls and boys, and illegal substance consumption for girls and boys. Our main finding is that girls attending high school at night present a higher probability of getting an abortion and start having sex at a younger age than girls attending high school in the morning or in the afternoon shifts. The effects are large and statistically significant: girls going to school at night are about 20 percentage points more likely to initiate sex by the age of 18 and 8 percentage points more likely to get an abortion relative to girls going to school at daytime. We do not find clear associations between attending high school at night and intercourse initiation for boys or substance consumption for girls and boys. The random assignment of shifts, the presence of very few non compliers, and the fact that in our sample there are no students that rejected an offer to study at this school after the shift was assigned, suggest that the link between high school shift and risky behavior is causal.

We then investigate the underlying mechanisms that link the late starting times and entry into risky behavior for girls. We source on the literature that studies the determinants of risky behavior in adolescence to identify the potential mechanisms behind our main effects and find empirical support to the mechanism of parental supervision. We present three pieces of evidence. First, we show that students going to school at night are under significantly less parental supervision than students going to school at daytime. Second, we show that the shift effect on sexual behavior disappears when we compare students in different high school shifts but with same levels of parental supervision, finding that suggests that the night effect operates through the reduction in parental involvement. Third, we empirically test the relevance of other determinants of risky behavior that have been studied in the literature as competing mechanisms and do not find support for any of them.

Our paper makes at least three contributions.

First, we contribute to the literature that studies the association between high school schedules and teenage risky behavior. To the best of our knowledge our paper is the first one to establish causal links between the two, and to identify the mechanism behind the high 
school starting time effect on risky behavior. Berthelon \& Kruger (2011) investigate the association between number of hours spent at school and the likelihood of teenage motherhood in Chile. They find that access to full-day schools reduces the probability of becoming an adolescent mother among poor families living in urban areas. Black et al. (2008) study whether increasing mandatory years of education through compulsory schooling legislation encourages women to delay childbearing in the US and Norway. They report evidence that increased compulsory schooling does in fact reduce the incidence of teenage childbearing. Our contribution to this literature is twofold. First, we show that the time of the day in which girls go to school has an effect on the age of sexual initiation and undesired fertility. Second, we are able to link this result to the fact that late starting times causes students to be under less parental supervision.

Second, we make a general contribution to the growing policy debate about the effects of late school start times. While previous papers have focused on the relationship between starting school later and academic performance, we focus on the interaction between high school start times and other important aspects of teenagers' lives, namely, entry into risky behavior and parental supervision. There is a strand of the literature that studies the relationship between later school start time, sleep patterns, and daytime performance and argues that teenagers would benefit from delaying school start time by reducing the negative effects of sleep deprivation. Notable papers include Boergers et al. (2014), Carrell et al. (2011), Heissel \& Norris (2017), and Pope (2016). These papers conclude that minor changes to schools schedules may have sizeable positive impacts on academic achievement. Another recent paper by Lusher \& Yasenov (2016) studies the cost effectiveness of a multiple shift school schedule in Eastern Europe and finds that attending school in the late block has only small negative effects on performance. The authors then conclude that double shift systems are a cost effective way of increasing the supply of education while saving resources. We contribute to this policy debate by making it evident that the evaluation of the effects of multiple shift systems and school starting times is incomplete without attention to the interaction between adolescents' mandated school schedules, the predetermined schedules of their families, and the accessibility to other markets in non school hours (like the market for unsafe sex or illegal substances). The main policy implication from this paper is, hence, that a proper evaluation of the effects of different high school schedules must pay attention to how school schedules interact with other markets in the particular context where those evaluations are implemented.

Third, we also make a contribution to the literature on the determinants of teenage risky behavior that shows that family and the social environment of a teenager influences individual risky behavior. The CASA at Columbia University annual reports have consistently showed that having family dinners more than twice a week is associated with a 
lower probability of drinking, smoking, or using drugs. ${ }^{5}$. As for social influences, many papers have identified significant peer effects in risky activities. Card \& Giuliano (2013) investigate the influence of best friends on sex and substance use initiation, concluding that having a close friend who initiated a risky activity increases the probability of taking up such activity. Soetevent (2006) surveys empirical papers identifying peer effects in the consumption of drugs, alcohol, and cigarettes. He concludes that peer effects on alcohol and cigarettes consumption are always large and positive, while peer effects on drug use are sometimes positive and sometimes negative. Peer groups in the papers surveyed by Soetevent (2006) include neighbourhood (Case \& Katz, 1991), school mates and school environment (Clark \& Lohéac (2007); Gaviria \& Raphael (2001)), and classmates (Soetevent \& Kooreman, 2007). In our paper we explore a novel cause for risky behavior, that is, attending school at nighttime, and we are able to link the effects to the family.

The rest of the paper is organized as follows. Section 2 describes the natural experiment and the instruments used to collect the data. Section 3 describes the variables used in the paper and presents randomization checks. Section 4 explains the estimation and inference strategies. Section 5 presents the main results. Section 6 discusses the mechanisms of the effects found. Finally, section 7 concludes.

\section{Experimental design and data collection}

This paper exploits the random assignment of students to school shifts and uses both administrative and survey data to conduct the analysis. While we rely on administrative data on shift assignment and total number of students by shift, our measures of risky behavior come from self-reported data. Unlike administrative records, survey data on risky behaviors may suffer from miss-reporting. To ameliorate this problem, the surveys are anonymous, self administered, and (only in the case of the survey of alumni) online.

\subsection{Randomization of high school shift}

In order to assess the causal impact of school shift on adolescence attitudes towards sex and substance consumption we take advantage from a natural experiment in a high school in the city of Buenos Aires. The high school Escuela Superior de Comercio Carlos Pellegrini (hereafter ESCCP) assigns incoming students to morning, afternoon, or night shifts through a public lottery. We describe the details of the experiment below.

ESCCP is one of the most prestigious and biggest public high school in the city of Buenos Aires, that directly depends on Universidad de Buenos Aires, the largest university in

\footnotetext{
${ }^{5}$ CASA's reports were accessed at www.casacolumbia.org/templates/publications_reports.aspx.
} 
Argentina. As every high school in Buenos Aires, ESCCP has a five-year curriculum. Courses at ESCCP are taught in three shifts: the morning shift (from 07:30 am to 12:00 pm), the afternoon shift (from 12:30 pm to $5 \mathrm{pm}$ ), and the evening shift (from 05:20 pm to 09:40 $\mathrm{pm})$. Because of its renowned quality of education and because tuition is free, every year the school faces an excess demand of first year applicants. Among all applicants, eligible students are chosen according to their performance in admission examinations in Literature, Mathematics, History, and Geography. Once students are admitted, school authorities split them among 15 opening classes so that class size is homogeneous. This process is made in two steps.

The first step is to allocate each incoming student to one of the three school shifts. For the sake of transparency, shift allocation is made at a public lottery session held at the beginning of the first academic year, before classes begin. In this session, each incoming first year student is randomly assigned to one of the three shifts they have to attend during the five years of high school. An exception is made to a minority of students that is allowed to choose the shift they desire to attend throughout high school based on their performance on the admission examinations and family background. ${ }^{6}$ Once shift has been assigned ESCCP authorities strictly forbid any shift change or shift swap between any two students. However, every year a few exceptions are made and some students manage not to comply with the shift assigned by the lottery. Although non-compliance rates are very low (as we will show later in section 3), our empirical strategy (described in section 4) explicitly deals with the presence of non compliance.

The second step in the determination of classes is to split the stock of students allocated to each shift into five classes. School authorities in each shift distribute students so that class size and gender are balanced among classes.

At the end of the process, 15 classes are formed at the beginning of the first year. The composition of classes is expected not to change for the whole duration of high school, meaning that, except from non-compliers or dropouts, a student's classmates are the same in all five years of high school. It is worth mentioning that unlike students, teachers are not randomized into the different school shifts or classrooms. However, administrative records reveal that the vast majority of school teachers teach in more than one shift and that more than $40 \%$ of teachers teach both at daytime and nighttime shifts.

\subsection{The 2013 cohort survey}

\footnotetext{
${ }^{6}$ The rules for lottery exemption have changed over time. For example, for some cohorts, students with the highest marks in the admission examinations were allowed to choose the shift they wanted to attend. In other years, students with older siblings in the school or with parents working at the school were allowed to choose to attend the same shift as their relatives work or attend school.
} 
The data was obtained from a voluntary and anonymous survey taken by ESCCP fifth year students. The survey was designed by the authors and tested through a pilot survey (we describe the pilot survey in the next subsection). The survey was taken by all high school students attending their fifth year in 2013 (mainly 17 and 18 year-old students) that were present the day of our visit. Out a total of 381 students enrolled in fifth year in 2013 the survey was answered by 318 students ( $83.4 \%$ of the population). It is worth noticing that students did not know in advance that they would be subject to a survey.

The survey was administered early in September 2013, at the beginning of the last trimester before graduation. ${ }^{7}$ The instrument was designed to measure treatment assigned, treatment received, outcomes related to sexual behavior and substance consumption, a set of pretreatment characteristics, and a set of potential mechanisms for the impact of high school shift on the outcomes.

Information on treatment assigned and treatment received was gathered through a series of questions that allow us to identify those students that were exempt from the lottery and those students that did not comply with the shift assigned. First, students were asked what shift they were drafted to in the shift lottery session. Multiple mutually exclusive choices were "I was exempt from the draft", "morning", "afternoon", and "evening". Second, respondents were asked what shift they actually attended in the first academic year. Last, students were asked if they moved to another shift after the first year and if so, in which academic year.

To gather pre-treatment characteristics we asked students about age, gender, characteristics of the primary school they attended, and the education of their parents. To measure the outcomes of interest, we asked all students about their sexual initiation and current consumption of alcohol and drugs and to female students if they had ever had an abortion. Finally, in order to test for possible mechanisms of the impact of school shift on risky behavior, we asked students about their interaction with their parents, their nightlife exposure, characteristics of their friends, and labor market participation.

\subsection{Pilot survey}

In April 2010 we administered a pilot survey to test the accuracy of the questions included in the final 2013 survey. In order to avoid contamination between the subjects that would participate in the two surveys, we not only performed the pilot survey sufficiently before the 2013 survey (more than three years before) but also, and critically, we aimed the pilot survey to the set of students that were already graduated from the school. That is, in 2010 we distributed the survey among former students that graduated from the school between 1983

\footnotetext{
7 In Buenos Aires the academic year starts early in March and ends early in December.
} 
and 2009. Given this design, it is extremely unlikely that subjects in the 2013 survey were aware of the existence or contents of the survey beforehand.

The pilot survey included the same questions as the final survey on treatment, outcomes, and pre-treatment characteristics. It was released by e-mail by the ESCCP Office of Graduate Students to all the school graduates. Given this way of distributing the survey, the low response rate ended up being a big concern. In effect, the pilot survey was answered by 405 former students that graduated between 1983 and 2009, approximately $4 \%$ of the total graduates in these cohorts.

In spite of the low response rate, a convenient feature of the pilot survey is that it allows us to measure sexual behavior and substance consumption of graduates from cohorts other than the 2013 cohort. Hence, a nice by-product of the data gathered through this pilot survey is that it allows us to evaluate the external validity of the main effects for the 2013 cohort, by allowing for the study of the effects of interest on cohorts graduating between 1983 and 2009.

\section{Summary statistics and randomization check}

In this section we describe the data and present evidence supporting the validity of the shift assignment as random. We consider the potential problems associated to attrition, treatmentcontrol balance of pre-treatment characteristics, and non-compliance, and we conclude that none of them are likely to undermine the main results of the paper.

In what follows, we exclude from the analysis of, both the main and the pilot surveys, the students that were exempt from the shift assignment lottery given that our empirical strategy is based on the random assignment of shift. Excluding these students does not pose any threat to our identification strategy. First, almost $90 \%$ of the students that are allowed to choose shift do so because they have older siblings in the school and can only attend the same shift that was (randomly) assigned to their siblings. Second, in table 7 discussed in section 6 of mechanisms, we show that those excluded from the sample do not differ from the experimental sample in pre-treatment characteristics.

The final sample consists of the 263 fifth year students (164 males and 99 females) in the 2013 cohort and 300 alumni (134 males and 166 females) from the 1983-2009 cohorts that answered the survey and were assigned their shift through the public lottery. Table 1 summarizes the number of students by gender, lottery assignment (variable Randomized into the Night) and the percent of years the student actually attended the night shift (variables High School at Night) for the sample of 263 students that participated in the lottery in the main sample. 
Table 2 summarizes the data and provides a preview of the main results of the paper.

\subsection{Summary statistics}

The first column of table 2 shows summary statistics (mean and standard deviation) of the variables used in this paper (the attrition and treatment indicators, pre-treatment characteristics, outcomes, and mechanisms). Pre-treatment characteristics are Primary school full time, morning, or afternoon (three dummy variables that take value one if the student attended the primary school full time, in the morning shift, or in the afternoon shift, respectively); Primary school public (a dummy variable that takes value one if the student attended the primary school at a public institution); Birth year (the year the student was born); Parents have higher education (a dummy variable that takes value one if at least one of the student's parents went to college); and Female (a dummy variable that takes value one if the student is a female). Outcomes are Initiated (a dummy variable that takes value one if the student reports having ever had sex, and it is measured on the 2013 cohort sample), Age at sexual initiation (a count variable indicating the age at which the person had their first intercourse experience, and it is measured for the 1983-2009 cohorts), Abortion (a dummy variable that was only measured on females and that takes value one if the girl reports having ever got an abortion), Drugs (a dummy that takes value one if the student reports that in a typical week (s)he consumes marijuana, cocaine, other hallucinogenic substances, or smokes), and Alcohol (a dummy that takes value one if the student reports that in a typical week (s)he consumes alcoholic drinks, like beer, wine, white spirits, and bitters). Finally, we consider several competing mechanisms that were only measured in the main survey of fifth year students in the 2013 cohort. The mechanisms we consider are Parental supervision (the proportion of the time the student is not at school in which at least one of his or her parents is not at work); Nightlife (the number of nights per week the students reports going out for recreation); Family dinners (the number nights per week the student reports having dinner with their family); Friends are older (the proportion of friends that are older than the student $)^{8}$; Friends use substances (the proportion of friends of the student that consume illegal substances) ${ }^{9}$; and Works (a dummy that takes value one if the student reports having a job).

The fraction of students not surveyed in the 2013 cohort is $18.8 \%$ (see our analysis of attrition below). Of the students participating in the study, about a third go to the night shift, a figure that provides a first piece of evidence of the success of the lottery assignment. As for pre-treatment characteristics, the most salient feature of both our samples is that students and

\footnotetext{
${ }^{8}$ Multiple choice options where Most of them are older than me, Most of them are my age, and Most of them are younger than me.

${ }_{9}$ Multiple choice options where All, More than half, Half, Less than half, and None.
} 
graduates in our study have highly educated parents: $90 \%$ of students in the 2013 cohort and $86 \%$ of graduates in the 1983-2009 cohorts have parents with a college degree. Regarding outcomes, almost half of the fifth year students in the 2013 cohort initiated sexually and the mean age of sexual initiation is between 17 and 18 years old, according to the statistics shown for the graduates sample. Moreover, 2\% of 2013 fifth year girls got an abortion, a figure that ascends to $9 \%$ when we consider graduate females.

\subsection{Attrition}

We only observe the characteristics of fifth year students and graduates that answered the survey. Hence, attrition (that is, the disappearance of a student from our sample between the time of the lottery assignment and the date of the survey) might undermine the exogeneity of the random assignment. In this subsection we consider two sources of attrition: dropping out from school before the fifth year and not answering the survey when still enrolled at ESCCP by the day of our visit. Unfortunately, we only count on administrative data to perform the attrition analysis on the main survey of 2013 fifth year students.

Administrative sources informed us that, for this cohort, drop-out rates (that is, abandoning the school between the lottery assignment and graduation date) are extremely low. First, in this cohort there was no incoming student that rejected admission after knowing the shift assigned by the lottery. Second, failing rates are extremely low. Although the school authorities treat this information as confidential, our sources assured us that in this cohort almost no student failed. ${ }^{10}$

Finally, attrition due to non-response rates is low and orthogonal to treatment assignment. The evidence is shown in the first line of table 2. While the first column shows the mean and standard deviation of being a non-respondent, the rest of the columns evaluates whether attrition rates differ by treatment status. In this table, Treatment refers to the set of students that was assigned the evening shift in the lottery session, Control refers to the set of students that was assigned either the morning shift or the afternoon shift in the lottery session, the statistic $E$ (Treatment $)-E($ Control $)$ is the difference in means between the treatment and the control group, and CI reports the $90 \%$ bootstrapped confidence intervals for the tests of differences in means. Attrition rates are 2 percentage points lower in the treatment group, but the difference is not statistically significant at the standard levels. An additional test of attrition is to investigate whether attitors differ in baseline characteristics. Unfortunately, we only have an imperfect measure of the gender of attritors, as some observations are missing.

\footnotetext{
10 ESCCP rules indicate that when a student fails a course she must leave the school. However, given the selection process, there are almost no failing students.
} 
However, when we exclude missing observations, we confirm that attritors and non-attritors are equally likely to be females.

All things considered, we conclude that attrition is unlikely to have undermined the validity of the randomization or to bias the main results of the paper. However, we cannot make a similar assessment regarding the results obtained from the pilot survey due to the small sample size.

\subsection{Non-compliance}

Another potential source of bias is non-compliance, that is, attending a shift different from the one assigned by the lottery. In table 2, High School at Night is our treatment received variable and is the proportion of academic years the student attended the evening shift. ${ }^{11}$ The table reveals that compliance in our post-attrition samples is extremely high: students randomized into the night shift are 90 and 67 percentage points more likely to attend the night shift relative to students randomized into daytime shifts for the 2013 cohort and the 19832009 cohorts, respectively. Table 3 confirms these results in regression form. In both samples being randomized into the night shift makes it more likely to attend the night shift, and the effects are quantitatively important and highly significant.

Even when compliance in our sample is high, in our empirical strategy we correct for the potential non-compliance bias by instrumenting treatment received with treatment assigned (see section 4 for details).

\subsection{Treatment-control balance}

An implication of random assignment is that the pre-treatment characteristics should not be correlated with lottery assignment. To check this implication we run a regression of randomized shift on the set of pre-treatment characteristics and perform a test of joint significance, which we report in table 2 . The second column in table 2 shows the t-tests for all students, the third column for females, and the forth column for males. For the 2013 cohort, pre-treatment characteristics are not jointly significant to explain randomization status, with a $\mathrm{p}$-value of the joint F-test of 0.327 . For the sample of graduate students from cohorts 1983 to 2009, pre-treatment characteristics are not jointly significant to explain randomization status, with a p-value of the joint F-test of 0.233 . We, additionally, report tests of balancing of pretreatment characteristics by treatment status. In general pre-treatment characteristics are

\footnotetext{
${ }^{11}$ We construct this variable as a proportion given that there are 13 students that moved to another shift between the first and the fifth year and hence spent some years in the evening shift. All results hold when we consider an alternative definition of High School at Night as a dummy variable that takes value one if the student ever attended the evening shift.
} 
balanced between treatment and control groups and the tests are highly robust to bootstrap correction for lack of power due to a small sample. In the 2013 sample, the only exception is Female. The test indicates that being randomized into the evening shift is associated with a lower probability of being a female relative to being randomized into daytime shifts. Even though the effect is not too big, we would worry that less risky girls change their shift or drop out from the school after knowing that they were assigned to the night shift. Based on the evidence presented in the two previous subsections, there is no differential attrition of females across treatments so we conclude that the higher male-to-female ratio in the treatment group is not due to non-random attrition (on the contrary, we showed evidence that attrition due to non-response rates is higher in the control group). Moreover, our instrumental variables estimation accounts for potential non-compliance bias. Finally, in all specifications below we control for gender. For the pilot survey, most pre-treatment characteristics are balanced (with the exception of Parents have higher education, which effect is small and negative). The balancing of pre-treatment characteristics yields similar conclusions within gender. The only exception parental education for females in the 2013 cohort. For this cohort, females that go to school at night are more likely to have college educated parents (a finding that would work against our main results).

We conclude that for the 2013 cohort the lottery assignment of school shift, the insignificance of attrition and non-compliance, and the balancing of pre-treatment characteristics indicate that the results presented below are not subject to significant sources of selection bias. For the 1983-2009 cohort, nevertheless, the low response rate and the impossibility of checking balancing of attrition rates makes us cautious about interpretation of results from the pilot survey and hence we take them as a robustness check for the main results of this paper.

\section{Empirical strategy}

The main objective is to identify the causal relationship between studying at night and adolescents' attitudes towards sex and substances by gender. Formally, the impact of attending high school at night on risky behavior is captured by estimating the following equation:

$$
\text { RiskyBehavior }_{i}=\beta+\text { SEvening }_{i}+\gamma X_{i}+\epsilon_{i}
$$

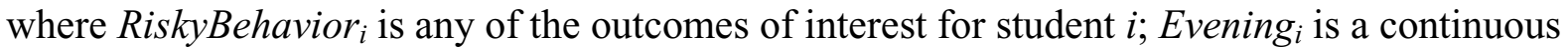
variable that captures the proportion of academic years the student attended the evening shift; ' is the casual reduced form parameter of interest; $X_{i}$ is the matrix of student $i$ pre- treatment characteristics summarized in table 2; and $\tilde{o}_{i}$ is an individual level random error term assumed to be uncorrelated with Evening . $_{i}$ 
Evening is potentially endogenous in model (1). Adolescents with higher propensity to engage in unsafe sex or consuming substances might have a preference for night life or for having less parental control and, therefore, might self-select into the evening shift. The natural experiment described in section 2 provides for a source of exogenous variation for Evening given that in our sample high school shift is randomly assigned. However, as shown in section 3, compliance with the lottery assignment is not perfect. To account for the presence of non-compliance, we use the randomly assigned shift as an instrument for the shift actually attended. As shown in Angrist et al. (1996), the Two Stages Least Squares (2SLS) estimator recovers the Local Average Treatment Effect (LATE), a parameter that estimates the effect of shift attended on those students whose shift attended is influenced by the lottery assignment. Our estimation strategy is, hence, twofold. First, we estimate the Intention to Treat (ITT) parameter by estimating ' in equation (1) by Ordinary Least Squares (OLS) when Evening $_{i}$ is specified as the school shift assigned to student $i$ by lottery. Second, we estimate

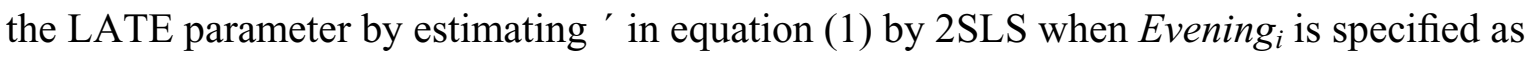
the school shift that student $i$ actually attended and it is instrumented with the shift assigned through the lottery. The first stage of the 2SLS approach is very strong as evidenced in table 3. This table reports the OLS estimates from a regression of High School at Night on Randomized into the Night (our instrumental variable, a dummy that takes value one if the student was assigned to the night shift thorough the lottery) and pre-treatment characteristics as covariates. In column (1) we report results for the 2013 cohort while in column (2) we report results for the pilot sample of alumni from 1983-2009 cohorts. The estimates of the first stage suggest that students that have been randomized into the night are 90 and 67 percentage points (respectively) more likely to attend the night shift relative to their peers in the daytime shifts and the effect is highly significant.

To test for the significance of the parameters estimated, we pursue two strategies. First, given that we are dealing with a small sample, we bootstrap confidence intervals for the parameters of interest. Second, given that for outcomes Sexual initiation and Substance consumption we analyze the Evening effect separately for males and females we additionally perform joint tests of the hypotheses across gender following the Romano \& Wolf (2005) step-down procedure. We do this because when we split the sample by gender, the number of hypothesis being tested increase, which raises the concern of increasing the Family Wise Error (FWE), that is, of detecting significant effects in some of the hypothesis due to mere chance. ${ }^{12}$

\section{Results}

\footnotetext{
${ }^{12}$ Formally, Romano \& Wolf (2005) define the FWE as the probability of falsely rejecting a proportion $\frac{\alpha}{n}$ of true hypothesis when testing simultaneously a family of $n$ hypothesis, each at level $\alpha$.
} 
Table 4 shows the main results of this paper: the estimation of equation (1) for all the outcomes of interest, by gender. The panel A in the table shows the results for the sample of fifth year students in the 2013 cohort, while the panel B reproduces the results for the 19832009 cohorts of graduate students. Columns (1) to (4) and (7) to (10) show results for females and columns (5), (6), (11), and (12) for males. Specifications (1), (3), (5), (7), (9), and (11) report the estimates of the ITT parameter, while specifications (2), (4), (6), (8), (10), and (12) report the estimates of the LATE parameter. All regressions include covariates. Results in specifications without covariates are very similar. ${ }^{13}$

\subsection{The 2013 cohort}

We start by exploring the effect of going to school at night on the probability of sexual initiation by age 18 in the whole sample of students and we do not find significant effects. One possibility to explain this result is that there is heterogeneous treatment effects by gender. As we will discuss in section 6, different attitudes towards sex across genders may result from cultural factors, stigma, or (as turns out to be supported by our data) from differential parental investments. In our main results, therefore, we explore treatment effects by gender.

Models (1) to (4) in panel A of table 4 refer to the sexual behavior of females. The ITT estimates indicate that girls that are randomized into the night shift are 20 percentage points more likely to have initiated sexually by the age of 18 and 7.6 percentage points more likely to get an abortion than comparable girls going to school at daytime. Furthermore, the LATE estimates suggest that girls that are induced to go to high school at night by the lottery assignment are 21.3 percentage points more likely to have initiated sexually and 8.1 percentage points more likely to get an abortion than girls complying with the daytime assignment of shift. All effects are significant at the $10 \%$ level.

For males we cannot measure the variable Abortion given that boys might be unaware of a terminated pregnancy by a (former) sexual partner. In models (5) and (6) in panel A of table 4 we measure sexual initiation. The impact of going to school at night on sexual behavior of males is opposite to the impact on the sexual behavior of girls. Boys randomized into the evening shift are 15.8 percentage points less likely to have initiated sexually relative to boys in the daytime shifts. Moreover, the effect for complier boys indicates that attending the night shift causes boys to be 17.9 percent points less likely to initiate sexually. All effects that are significant at the $5 \%$ level.

\footnotetext{
${ }^{13}$ All results mentioned but not reported are available from the authors upon request.
} 
Finally, for both boys and girls we do not find significant effects on substance consumption although the effects are positive.

\subsection{External validity}

It is important to understand to what extent our results and policy implications extrapolate to a more general population.

First, we investigate if our results could be specific to the 2013 cohort. To that end, in panel B of table 4 we report the night shift effects for the respondents of the pilot survey that graduated between 1983 and 2009.

For females, the cohorts of graduates show a similar patterns than the 2013 cohort. In effect, the ITT estimates in models (7) and (9) indicate that girls that were randomized into the night shift started having sex almost 0.8 years before girls randomized to daytime shifts and are 14.2 percentage points more likely to have got an abortion. These effects are significant at the $10 \%$ level. Similarly, the LATE estimates suggest that girls that went to high school at night started having sex around one year before girls from the daytime shifts and are 20.2 percentage points more likely to have got an abortion than girls graduating from the daytime shifts. These effects are significant at the 5\% level. In the pilot sample we similarly do not find significant effects on substance consumption although the effects are positive.

These results suggest that females in the 2013 cohort follow a pattern of risky behavior that is consistent with what is observed for females in the 1983 to 2009 cohorts of graduate students. Both girls attending high school at night and women that graduated from high school at night, present a riskier sexual behavior than their female counterparts in the daytime shifts. For both samples, moreover, there are no differences in the consumption of substances between females attending the night shift and females attending the daytime shifts. With the caveat of the low response rate in the pilot survey in mind, we conclude that this consistency across surveys provides some support to the external validity of the main results for females.

For boys, on the contrary, the night shift effects do not seem consistent across surveys, and hence we are more cautious about the external validity of these results. In effect, our estimates indicate that there were no differences across shifts in the age of sexual initiation for males that graduated from cohorts 1983-2009.

Second, we compare our samples of students and alumni to the average population in Argentina in order to investigate if our samples are representative of the more general population. 
First, in terms of sexual behavior our sample resembles the national averages. For example, according to the Argentinean Ministry of Health the mean age at sex initiation in the country is 17.3 years old, similar to the figure of 17.4 in our sample of alumni (that includes people of comparable age groups). When we restrict attention to adolescents, the mean age at sex initiation is 15.5 years old in the country and 15.8 in our sample of students (MINSAL, 2017). ${ }^{14}$

Second, in other demographic and economic characteristics our sample is most representative of urban middle income families. For example, according to the 2015 Argentine Permanent Household Survey (henceforth EPH for its name in Spanish), almost 50\% of middle income families in Buenos Aires City have both the head of the household and their spouse working full time outside of the household. Similarly in our sample we observe $55 \%$ of families with both mother and father working full time. Moreover, in our sample we observe $55.89 \%$ of households where the mother has a college degree and 50.95\% households where the father has a college degree. These figures overestimate but are fairly close to the $2015 \mathrm{EPH}$ figures where $50.53 \%$ of females and $39.18 \%$ of males older than 20 years old have a college degree.

We conclude that our results have external validity for middle income groups but should be taken with caution when applied to lower income environments.

\subsection{A note on inference}

Within each of the samples (that is, within the samples of the 2013 cohort and the 1983-1009 cohorts) and for the sexual initiation outcome, we test jointly the hypotheses that the night shifts effects are positive for females and negative for males. ${ }^{15}$ The Romano \& Wolf (2005) test suggests that all effects are jointly significant ( $p$-values for females are less than 0.11 and for males are between 0.4 and 0.5 ). The positive result of the joint test provides evidence that it is not because of mere chance that we are able to detect significant evening effects when we split the sample between females and males: the effects continue to be significant even when we control for the FWE.

\section{Mechanisms}

The finding of riskier sexual behavior for girls going to school at night but not for boys, and of no differential behavior in consumption of substances across shifts and gender motivates

\footnotetext{
${ }^{14}$ Data on abortion rates are scarce because of being an illegal practice in Argentina.

${ }^{15}$ We also perform the Romano-Wolf two sided joint tests, but we loose some power due to the small amount of observations and the high amount of hypotheses being tested jointly: while the effects for males continue to be significant, we fail to detect a significant effect for females in the two sided test.
} 
the exploration of the mechanisms that explain these particular patterns. Adolescents' engagement in risky behavior can be understood as a simple constrained choice problem: adolescents extract utility from risky goods, such as having unprotected sex or consuming substances, and the choice of consumption of those goods is subject to the possibility of accessing those goods. In the light of this model, the night shift effect operates through a relaxation of the constraint for risky behavior: if students going to school at night have the same preferences for risky behavior as students going to school at daytime (which is assumed given the random assignment of shift), but have easier access to risky goods because of going to school at a different time of the day, we would expect students going to school at night to engage in more risky behavior. In this section we explore some instances of easier access to risky goods of students going to school at night. We explore parental supervision, exposure to night life, family and friendship influences, labor market participation, and differential quality of education across high school shifts, and conclude that the evidence only favors the mechanism of lower parental supervision.

\subsection{Parental supervision and opportunities for sex}

The literature on the effect of parental involvement suggests that parental control and monitoring reduces the likelihood of engaging in risky behavior. Many papers have found that laws requiring written parental consent from female minors before getting an abortion significantly reduce adolescent pregnancy (Levine, 2003) and the incidence of sexually transmitted diseases among adolescents (see, for example, Klick \& Stratmann (2008)). These papers argue that having to discuss sexual matters with parents make adolescents more careful in their sexual behavior (Colman et al., 2013). Other papers in the Health literature claimed that the perception of higher parental monitoring in adolescents is associated to lower sexual risks and lower consumption of substances (see, for example DiClemente et al. (2001)).

We asked students to report the work schedule of their father and mother and construct our measure of parental supervision as the proportion of time out of school that at least one of his or her parents is not at work. To construct this variable, we consider that apart from sleeping time there are three shifts in a day (morning, afternoon, and night). Since all students go to school in exactly one of these shifts and parents can work in any of these shifts or not work at all, the proportion of time out of school under parental supervision can take three values: zero, half, or one. A value of zero means that the two parents are at work when the student is not at school. This means that in the two shifts that the student is not at school, her parents cannot be monitoring her because they are at work. A value of half means that there is one out of two shifts when the student is not at school and at least one of her parents can be 
supervising her because they are not at work. Finally, a value of one means that when the student is out of school there is always at least one parent available for supervision. ${ }^{16}$

In Panel A of table 5 we provide evidence that girls and boys going to school at night are less likely to be under parental supervision relative to students going to school at daytime. For girls assigned the night shift the time out of school under the supervision of her parents is reduced in $36.5 \%$. Similarly, being assigned the night shift causes parental supervision of boys to be reduced in $26.4 \%$ of the time out of school.

An observational implication of the mechanism of parental supervision is that the night shift effect should disappear if we consider students that are under full supervision of their parents. We hence define the variable full supervision as a dummy that takes value one if parental supervision is one and zero otherwise. To account for the differential effect of high school shift across students with different levels of parental supervision we estimate the following regression model:

$$
\text { RiskyBehavior }_{i}=\beta+\alpha \text { Evening }_{i} * \text { FullSupervision }_{i}+\delta \text { Evening }_{i}+\eta \text { FullSupervision }_{i}+\gamma X_{i}+\epsilon_{i}
$$

Under the null hypothesis that parental supervision is the underlying mechanism, the effect of the night shift on risky behavior (that is, ' $+ \pm *$ FullSupervision) should be zero when full supervision takes value one. We hence test the hypothesis that ' $+ \pm=0$ and conclude that the data does not reject it. We present the results of the test in Panel B of table $5 .{ }^{17}$ The p-value of the F-test at the bottom of table 5 indicates that being exposed to the same levels of parental supervision, there is no difference in risky behavior between students from the night shift and students from the daytime shifts. ${ }^{18}$

Not only does our evidence support the mechanism of parental supervision, but also this mechanism seems to be consistent with our finding of differential sexual initiation behavior across genders. In particular, there is an important body of literature indicating that parents care more about the sexual behavior of daughters than of sons. Nagamatsu et al. (2008) present evidence that parental monitoring was statistically associated with delay of first

16 Of course this measure is potential because we cannot observe if when both parents and students are out of work or school they are in fact together at home. Our evidence, thus, provides an upper bound on the association between high school shift and time under parental supervision.

17 For this test we define the variable full supervision because as long as the student has some time without the presence of their parents, the possibility still exists that she engages in risky behavior. Our conclusions, however, hold when we consider an alternative interaction model with variable supervision in place of full supervision and test for no night shift effect when supervision takes the values of half or one.

${ }^{18}$ We perform an alternative test: we restrict the sample to students with value of one of full supervision and test the significance of the night shift effect. We confirm that the night shift effect disappears in the subsample of students under parental supervision. However, the low sample size makes us prefer the more powerful test reported in table 5 . 
intercourse in female students. Wamoyi et al. (2011) find that girls receive more supervision in issues related to sexual behavior compared to boys. In line with our explanation, they report evidence that spending little time with their children precludes parents from effectively monitoring their children. Rani et al. (2003) report that girls were more often discouraged by parents or siblings from engaging in sex, while boys were, on the contrary, encouraged by family to engage in premarital sex. It is expected, then, that lower parental supervision is associated to riskier sexual behavior for girls but not for boys given that parental care for boys was not important to begin with. This is precisely what we find in this paper, once we establish that parental supervision is the mechanism underlying the night shift effect. ${ }^{19}$

The mechanism of parental supervision is reinforced by another potential mechanism that we cannot rule out: the sex ratio in the night shift favors females. As table 2 reveals, there are significantly less females in the night shift relative to the daytime shifts. This could imply that females in the night shift (that are in excess demand) are faced with more opportunities to have sexual partners than boys in the night shift (that are in excess supply). This alternative mechanism is also consistent with the differential effects found for boys and girls. The evidence, then, suggests that females in the night shift are faced with more opportunities to engage in risky sexual, both because they are under less parental supervision and because they are in higher demand.

All in all, our evidence supports the mechanisms of parental supervision and differential sex ratio. Students going to school at night are exposed to less parental supervision because when parents are at work during daytime, students are home alone, and when parents come back from work in the evening, students are at school. If parents have interest in preventing their daughters from engaging in risky behavior, less time under parental supervision would imply higher accessibility to risky behavior. Reinforcing this, our evidence suggests that girls are indeed faced with more partner choices.

\subsection{Other potential mechanisms}

We also explore other family and social influences identified in the literature(reviewed in section 1) as competing mechanisms. To test for these competing mechanisms, we explore the relationship between going to school at night and the influence of nightlife peers, family dinner, and the influence of friends. Furthermore, taking into account the particular characteristics of the environment where we conduct our study we also consider labor market

${ }^{19}$ We are able to provide some empirical support to the statement that parents care more for the behavior of their daughters than of their sons. We asked students the frequency with which they have conversations with their parents on important aspects of their lives, such as sexual issues. We estimate the correlation between being a female and talking frequently with parents and find that girls are between 24 and 27 percentage points more likely to have conversations with their parents and the effects are significant at the $1 \%$ level. 
participation of students. Table 6 shows the result of estimating a regression similar to (1) but with the considered mechanisms as the dependent variable. To save space, in table 6 we only report estimates of the ITT parameter, which are extremely similar to the estimates of the LATE parameter. ${ }^{20}$ We do not find significant differences across shifts in these dimensions.

Finally, we explore whether there is something systematically different between the night and the daytime shifts within the school, that could explain engagement in risky behavior. We considered differential quality of education across shifts and classroom peer effects. First, we cannot reject the hypothesis that the quality of education is the same across shifts based on two pieces of administrative evidence: most teachers in the school teach in both the daytime and the night shifts, and the academic curriculum (courses and contents) is the same for all shifts. ${ }^{21}$ Second, we consider differential classroom peers. In this school, classmates across shifts could differ because there is a small proportion of students that are allowed to choose shift. If students that are allowed to choose shift choose a daytime shift more frequently, and are systematically different from the students that are assigned shift by lottery, then peer effects within the classroom might explain the higher probability of engagement in risky behavior in the night shift. However, the evidence does not support this possibility. On the one hand, as mentioned before, almost $90 \%$ of the students that are allowed to choose shift do so because they have older siblings in the school and are forced to attend the same shift that was (randomly) assigned to their siblings. Moreover, the choice of shift is pretty balanced: among students that are allowed to choose the shift, 37.78\% decides to go to the morning shift, $33.33 \%$ to the afternoon, and $28.89 \%$ to the night shift. On the other hand, we cannot reject the null hypothesis that pre-treatment characteristics for the students in our sample, that are assigned their shift by lottery, are similar to pre-treatment characteristics for students that can choose their shift. Table 7 displays the analysis of balancing of pre-treatment characteristics between the two samples of students and shows that the two groups are not significantly different in all pre-treatment variables.

\section{Concluding remarks}

\footnotetext{
20 In table 6, Nightlife refers to the number of nights the student reports going out for recreation at night; Family dinners captures the number of dinner the student shares with his or her family per week; Friends are older indicates the proportion of the student's friends that are older than him or her, with multiple choice options being most of them are older than me, most of them are my age, and most of them are younger than $m e ;$ Friends use substances captures the proportion of the student's friends that consume substances, with multiple choice options being all, more than half, half, less than half, and none; and Works is a dummy variable indicating whether the student works in the labor market.

${ }^{21}$ It could still be the case that teachers teaching long hours are more tired in the night shift and that might affect quality of education. However, this possibility is hard to reconcile with the differential shift effect for girls and boys.
} 
Multiple shift school systems have been gaining popularity, especially in the developing world, since they serve the purpose of increasing the supply of educational services while saving on infrastructure resources. In Argentina, for example, the two most prestigious and biggest public high schools in the city of Buenos Aires are multiple shift schools that include a night shift.

While some research has shown that later start times might have more academic benefits than harms, the debate is incomplete without considering that different school schedules may disrupt other aspects of teenagers' lives. We contribute to the understanding of the overall effects of having groups of students going to school at different times. In this paper we focus on how late high school start times affect participation in the market for risky sex and the possibility of parental supervision. In our context, starting school late in the evening implies that students are alone at home during the day. The main result from our paper is that starting school at a time when parents come back home from work causes girls to increase their participation in the market for risky sex. We are able to link this result to the decreased parental supervision these girls face given the random variation in the time students meet their parents at home. We believe our conclusions extend to any context where markets for risky behavior are open in non school hours and where families have schedules that are predetermined with respect to school schedules.

The policy implications from this paper are twofold. First, regarding the effects of different school starting times, it is evident from our study that future evaluations should consider not only academic performance, but also, the participation of adolescents in markets open in non school hours. Second, regarding policies towards reducing adolescent risky behavior, our results suggest that parental supervision is an important determinant of entry into risky behavior. Hence, future policy looking forward to reducing teenage sexual risky behavior should focus on parental involvement.

\section{References}

Angrist, Joshua D, Imbens, Guido W, \& Rubin, Donald B. 1996. Identification of causal effects using instrumental variables. Journal of the American Statistical Association, 91(434), 444-455.

Berthelon, Matias E., \& Kruger, Diana I. 2011. Risky behavior among youth: Incapacitation effects of school on adolescent motherhood and crime in Chile. Journal of Public Economics, 95(1 - 2), $41-53$. 
Black, Sandra E., Devereux, Paul J., \& Salvanes, Kjell G. 2008. Staying in the Classroom and out of the maternity ward? The effect of compulsory schooling laws on teenage births. The Economic Journal, 118(530), 1025-1054.

Boergers, Julie, Gable, Christopher J, \& Owens, Judith A. 2014. Later school start time is associated with improved sleep and daytime functioning in adolescents. Journal of Developmental \& Behavioral Pediatrics, 35(1), 11-17.

Card, David, \& Giuliano, Laura. 2013. Peer effects and multiple equilibria in the risky behavior of friends. Review of Economics and Statistics, 95(4), 1130-1149.

Carrell, Scott E., Maghakian, Teny, \& West, James E. 2011. A's from Zzzz's? The Causal Effect of School Start Time on the Academic Achievement of Adolescents. American Economic Journal: Economic Policy, 3(3), 62-81.

CASA. 2005. The Importance of Family Dinners II. National Center on Addiction and Substance Abuse at Columbia University.

Case, Anne C, \& Katz, Lawrence F. 1991. The company you keep: The effects of family and neighborhood on disadvantaged youths. NBER Working Paper Series, WP 3705.

Clark, Andrew E., \& Lohéac, Youenn. 2007. "It wasn't me, it was them!" Social influence in risky behavior by adolescents. Journal of Health Economics, 26(4), 763 - 784.

Colman, Silvie, Dee, Thomas S., \& Joyce, Ted. 2013. Do parental involvement laws deter risky teen sex? Journal of Health Economics, 32(5), 873 - 880.

Conti, Gabriella, \& Heckman, JamesJ. 2014. Economics of Child Well-Being. Pages 363 401 of: Ben-Arieh, Asher, Casas, Ferran, Frones, Ivar, \& Korbin, Jill E. (eds), Handbook of Child Well-Being. Springer Netherlands.

DiClemente, Ralph J, Wingood, Gina M, Crosby, Richard, Sionean, Catlainn, Cobb, Brenda K, Harrington, Kathy, Davies, Susan, Hook, Edward W, \& Oh, M Kim. 2001. Parental monitoring: Association with adolescents' risk behaviors. Pediatrics, 107(6), 1363-1368.

Gaviria, Alejandro, \& Raphael, Steven. 2001. School-based peer effects and juvenile behavior. Review of Economics and Statistics, 83(2), 257-268.

Heissel, Jennifer, \& Norris, Samuel. 2017. Rise and shine: The effect of school start times on academic performance from childhood through puberty. Journal of Human Resources, 08157346R1. 
Jáuregui, M, Jeria, J, \& Retama, G. 2003. La educación de Jóvenes y Adultos en América Latina y el Caribe, Hacia un estado del arte.

Klick, J., \& Stratmann, T. 2008. Abortion access and risky sex among teens: Parental involvement laws and sexually transmitted diseases. Journal of Law, Economics, and Organization, 24(1), 2-21. cited By 19.

Levine, Phillip B. 2003. Parental involvement laws and fertility behavior. Journal of Health Economics, 22(5), $861-878$.

Livingston, Jennifer A., Testa, Maria, Windle, Michael, \& Bay-Cheng, Laina Y. 2015. Sexual risk at first coitus: Does alcohol make a difference? Journal of Adolescence, 43, 148 - 158.

Llorente, Juan Carlos. 2014. Programa de Inclusión y Terminalidad de la Educación Secundaria Para Jóvenes de 14 a 17 Años (PIT). Cuadernos de Educación, 12(12).

Louie, KS, De Sanjose, S, Diaz, M, Castellsague, X, Herrero, R, Meijer, CJ, Shah, K, Franceschi, S, Muñoz, N, \& Bosch, FX. 2009. Early age at first sexual intercourse and early pregnancy are risk factors for cervical cancer in developing countries. British journal of cancer, 100(7), 1191-1197.

Lusher, Lester, \& Yasenov, Vasil. 2016. Double-shift schooling and student success: Quasiexperimental evidence from Europe. Economics Letters, 139, 36 - 39.

MINSAL. 2017. Encuesta Nacional Sobre Salud Sexual y Reproductiva: Acceso y uso de métodos anticonceptivos.

Nagamatsu, Miyuki, Saito, Hisako, \& Sato, Takeshi. 2008. Factors Associated With Gender Differences in Parent-Adolescent Relationships That Delay First Intercourse in Japan. Journal of School Health, 78(11), 601-606.

Pope, Nolan G. 2016. How the Time of Day Affects Productivity: Evidence from School Schedules. Review of Economics and Statistics, 98(1), 1 - 11.

Rani, Manju, Figueroa, Maria Elena, \& Ainsle, Robert. 2003. The Psychosocial Context of Young Adult Sexual Behavior in Nicaragua: Looking through the Gender Lens. International Family Planning Perspectives, 29(4), pp. 174-181.

Romano, Joseph P., \& Wolf, Michael. 2005. Stepwise Multiple Testing as Formalized Data Snooping. Econometrica, 73(4), 1237-1282. 
Soetevent, Adriaan R. 2006. Empirics of the Identification of Social Interactions; An Evaluation of the Approaches and Their Results. Journal of Economic Surveys, 20(2), 193228.

Soetevent, Adriaan R., \& Kooreman, Peter. 2007. A discrete-choice model with social interactions: with an application to high school teen behavior. Journal of Applied Econometrics, 22(3), 599-624.

Terigi, F. 2012. Adolescentes y secundaria obligatoria. Centros de Escolarización de Adolescentes y Jóvenes (CESAJ).

Wamoyi, Joyce, Fenwick, Angela, Urassa, Mark, Zaba, Basia, \& Stones, William. 2011. Parental control and monitoring of young people's sexual behaviour in rural North-Western Tanzania: implications for sexual and reproductive health interventions. BMC public health, 11(1), 106.

Wellings, Kaye, Collumbien, Martine, Slaymaker, Emma, Singh, Susheela, Hodges, Zoé, Patel, Dhaval, \& Bajos, Nathalie. 2006. Sexual behaviour in context: a global perspective. The Lancet, 368(9548), 1706 - 1728.

Table 1 Number of students by gender and school shift

\begin{tabular}{|l|c|c|c|c|}
\hline & \multicolumn{3}{l|}{ Females } & \multicolumn{2}{l|}{} \\
\hline & \multicolumn{2}{|l|}{ Randomized into the Night } & 1 \\
\hline $\begin{array}{l}\text { High School at } \\
\text { Night }\end{array}$ & 0 & 1 & 0 & 1 \\
\hline 0 & 73 & 0 & 99 & 10 \\
\hline$\in(0,1)$ & 0 & 2 & 1 & 53 \\
\hline 1 & 0 & 24 & 0 & 64 \\
\hline $\mathrm{N}$ & 73 & 26 & 100 & \\
\hline
\end{tabular}

Notes: High School at Night is the percent of academic years the student attended the evening shift and can take value 0 if the student never attended the evening shift, 1 if the student attended the evening shift in all five years of high school, or a number between 0 and 1 (denoted $\in(0,1)$ in the table) if the student attended some high school years in the evening. Randomized into the Night is a dummy variable that takes value one if the student was assigned to the night shift thorough the lottery.

Table 2 Summary statistics, attrition, and balancing of pre-treatment characteristics

\begin{tabular}{|l|c|l|}
\hline & Mean & E(Treatment)-E(Control) \\
\hline & (Std.Dev. $)$ & {$[90 \%$ Bootstrapped $\mathrm{Cl}]$} \\
\hline
\end{tabular}




\begin{tabular}{|c|c|c|c|c|}
\hline & All & All & Females & Males \\
\hline \multicolumn{5}{|c|}{ Main survey: 2013 cohort } \\
\hline \multicolumn{5}{|c|}{\begin{tabular}{|l|l|} 
Attrition: & \\
\end{tabular}} \\
\hline \multirow{2}{*}{ Not surveyed } & 0.188 & -0.021 & n.a. & n.a \\
\hline & $(0.392)$ & {$[-0.096 ; 0.054]$} & & \\
\hline \multicolumn{5}{|l|}{$\begin{array}{l}\text { Treatment } \\
\text { indicator: }\end{array}$} \\
\hline \multirow[t]{2}{*}{$\begin{array}{l}\text { High School at } \\
\text { Night }\end{array}$} & 0.311 & $0.902^{* * *}$ & $0.938^{* * *}$ & $0.887^{* * *}$ \\
\hline & $(0.453)$ & {$[0.855 ; 0.950]$} & {$[0.868 ; 1.009]$} & {$[0.786 ; 0.987]$} \\
\hline \multicolumn{5}{|l|}{$\begin{array}{l}\text { Pre-treatment } \\
\text { characteristics: }^{a}\end{array}$} \\
\hline \multirow[t]{2}{*}{$\begin{array}{l}\text { Primary school } \\
\text { full time }\end{array}$} & 0.531 & 0.081 & -0.034 & 0.139 \\
\hline & $(0.5)$ & {$[-0.023 ; 0.190]$} & {$[-0.352 ; 0.284]$} & {$[-0.078 ; 0.356]$} \\
\hline \multirow{2}{*}{$\begin{array}{l}\text { Primary school } \\
\text { morning }\end{array}$} & 0.347 & -0.033 & 0.108 & -0.104 \\
\hline & $(0.477)$ & {$[-0.135 ; 0.070]$} & {$[-0.204 ; 0.420]$} & {$[-0.297 ; 0.089]$} \\
\hline \multirow{2}{*}{$\begin{array}{l}\text { Primary school } \\
\text { afternoon }\end{array}$} & 0.122 & -0.049 & -0.074 & -0.035 \\
\hline & $(0.328)$ & {$[-0.118 ; 0.021]$} & {$[-0.272 ; 0.124]$} & {$[-0.174 ; 0.104]$} \\
\hline \multirow[t]{2}{*}{$\begin{array}{l}\text { Primary school } \\
\text { public }\end{array}$} & 0.502 & -0.037 & -0.15 & 0.016 \\
\hline & $(0.501)$ & {$[-0.148 ; 0.075]$} & {$[-0.439 ; 0.140]$} & {$[-0.194 ; 0.225]$} \\
\hline \multirow[t]{2}{*}{ Birth year } & 1995 & -0.050 & -0.202 & 0.011 \\
\hline & $(0.801)$ & {$[-0.230 ; 0.131]$} & {$[-1.016 ; 0.611]$} & {$[-0.292 ; 0.314]$} \\
\hline \multirow[t]{2}{*}{$\begin{array}{l}\text { Parents have } \\
\text { higher education }\end{array}$} & 0.857 & 0.015 & $0.055^{* *}$ & 0.015 \\
\hline & $(0.351)$ & {$[-0.049 ; 0.080]$} & {$[-0.032 ; 0.141]$} & {$[-0.132 ; 0.162]$} \\
\hline \multirow[t]{2}{*}{ Female } & 0.553 & $-0.133^{* *}$ & n.a & n.a \\
\hline & $(0.498)$ & {$[-0.231 ;-0.035]$} & & \\
\hline \multicolumn{5}{|l|}{ Outcomes: } \\
\hline \multirow[t]{2}{*}{ Initiated } & 0.456 & -0.086 & 0.172 & $-0.179^{* *}$ \\
\hline & $(0.499)$ & {$[-0.195 ; 0.024]$} & {$[-0.01 ; 0.353]$} & {$[-0.303 ;-0.055]$} \\
\hline \multirow[t]{2}{*}{$\begin{array}{l}\text { Abortion } \\
\text { (females) }\end{array}$} & 0.020 & $0.08^{*}$ & $0.08^{*}$ & n.a \\
\hline & $(0.142)$ & {$[0.011 ; 0.149]$} & {$[0.011 ; 0.149]$} & \\
\hline \multirow[t]{2}{*}{ Drugs } & 0.521 & -0.041 & 0.086 & -0.099 \\
\hline & $(0.501)$ & {$[-0.152 ; 0.07]$} & {$[-0.118 ; 0.29]$} & {$[-0.237 ; 0.038]$} \\
\hline \multirow[t]{2}{*}{ Alcohol } & 0.757 & -0.010 & 0.033 & -0.025 \\
\hline & $(0.430)$ & {$[-0.106 ; 0.086]$} & {$[-0.137 ; 0.203]$} & {$[-0.147 ; 0.097]$} \\
\hline \multicolumn{5}{|l|}{ Mechanisms: } \\
\hline \multirow{2}{*}{ Supervision } & 0.555 & $-0.287^{* * *}$ & $-0.3649^{* * *}$ & $-0.249^{* * *}$ \\
\hline & $(0.338)$ & {$[-0.367 ;-0.206]$} & {$[-0.497 ;-0.23]$} & {$[-0.349 ;-0.15]$} \\
\hline
\end{tabular}

This article is protected by copyright. All rights reserved. 


\begin{tabular}{|c|c|c|c|c|}
\hline Nightlife & 0.259 & -0.021 & -0.032 & -0.009 \\
\hline & $(0.142)$ & {$[-0.049 ; 0.007]$} & {$[-0.074 ; 0.010]$} & {$[-0.048 ; 0.029]$} \\
\hline \multirow[t]{2}{*}{ Family dinners } & 0.813 & 0.006 & 0 & 0.004 \\
\hline & $(0.148)$ & {$[-0.025 ; 0.036]$} & {$[-0.05 ; 0.051]$} & {$[-0.037 ; 0.045]$} \\
\hline \multirow[t]{2}{*}{ Friends are older } & 0.112 & 0.001 & -0.051 & 0.04 \\
\hline & $(0.315)$ & {$[-0.065 ; 0.068]$} & {$[-0.186 ; 0.083]$} & {$[-0.042 ; 0.123]$} \\
\hline \multirow{2}{*}{$\begin{array}{l}\text { Friends use } \\
\text { substances }\end{array}$} & 0.707 & -0.079 & -0.001 & -0.086 \\
\hline & $(0.456)$ & {$[-0.18 ; 0.023]$} & {$[-0.158 ; 0.157]$} & {$[-0.215 ; 0.043]$} \\
\hline \multirow[t]{2}{*}{ Works } & 0.088 & -0.015 & 0.004 & -0.031 \\
\hline & $(0.284)$ & {$[-0.075 ; 0.045]$} & {$[-0.13 ; 0.139]$} & {$[-0.107 ; 0.046]$} \\
\hline \multicolumn{5}{|c|}{${ }^{a}$ Joint F-test $p$-value: 0.327} \\
\hline \multicolumn{5}{|c|}{ Pilot survey: 1983-2009 cohorts } \\
\hline \multicolumn{5}{|c|}{\begin{tabular}{l|l} 
Treatment & \\
indicator: &
\end{tabular}} \\
\hline \multirow[t]{2}{*}{$\begin{array}{l}\text { High School at } \\
\text { Night }\end{array}$} & 0.234 & $0.679^{* * *}$ & $0.696^{* * *}$ & $0.659^{* * *}$ \\
\hline & $(0.415)$ & {$[0.606 ; 0.752]$} & {$[0.477 ; 0.915]$} & {$[0.481 ; 0.836]$} \\
\hline \multicolumn{5}{|l|}{$\begin{array}{l}\text { Pre-treatment } \\
\text { characteristics: }^{b}\end{array}$} \\
\hline \multirow[t]{2}{*}{$\begin{array}{l}\text { Primary school } \\
\text { full time }\end{array}$} & 0.383 & 0.099 & 0.155 & 0.028 \\
\hline & $(0.487)$ & {$[0.000 ; 0.198]$} & {$[-0.0534 ; 0.363]$} & {$[-0.214 ; 0.270]$} \\
\hline \multirow[t]{2}{*}{$\begin{array}{l}\text { Primary school } \\
\text { morning }\end{array}$} & 0.432 & -0.067 & -0.107 & -0.016 \\
\hline & $(0.496)$ & {$[-0.169 ; 0.035]$} & {$[-0.317 ; 0.104]$} & {$[-0.263 ; 0.232]$} \\
\hline $\begin{array}{l}\text { Primary school } \\
\text { afternoon }\end{array}$ & 0.185 & -0.032 & -0.048 & -0.012 \\
\hline
\end{tabular}

Table 2 Summary statistics, attrition, and balancing of pre-treatment characteristics (continued)

\begin{tabular}{|l|c|c|c|c|}
\hline & Mean & \multicolumn{3}{l|}{ E(Treatment)-E(Control) } \\
\hline & (Std.Dev.) & \multicolumn{2}{l|}{$[90 \%$ Bootstrapped CI } \\
\hline & All & All & Females & Males \\
\hline $\begin{array}{l}\text { Primary school } \\
\text { public }\end{array}$ & $(0.389)$ & {$[-0.110 ; 0.047]$} & {$[-0.220 ; 0.124]$} & {$[-0.204 ; 0.180]$} \\
\hline & 0.575 & -0.060 & -0.093 & -0.015 \\
\hline Birth year & $(0.495)$ & {$[-0.161 ; 0.042]$} & {$[-0.319 ; 0.133]$} & {$[-0.258 ; 0.228]$} \\
\hline & 1981 & -0.820 & -1.031 & -0.582 \\
\hline $\begin{array}{l}\text { Parents have } \\
\text { higher education }\end{array}$ & $(7.318)$ & {$[-2.270 ; 0.630]$} & {$[-3.96 ; 1.903]$} & {$[-3.934 ; 2.770]$} \\
\hline
\end{tabular}

This article is protected by copyright. All rights reserved. 


\begin{tabular}{|c|c|c|c|c|}
\hline & $(0.351)$ & {$[-0.162 ;-0.008]$} & {$[-0.305 ; 0.051]$} & {$[-0.197 ; 0.115]$} \\
\hline \multirow[t]{2}{*}{ Female } & 0.553 & -0.050 & n.a. & n.a. \\
\hline & $(0.498)$ & {$[-0.153 ; 0.053]$} & & \\
\hline \multicolumn{5}{|l|}{ Outcomes: } \\
\hline \multirow[t]{2}{*}{$\begin{array}{l}\text { Age at sexual } \\
\text { initiation }\end{array}$} & 17.398 & -0.361 & -0.496 & -0.174 \\
\hline & (2.107) & {$[-0.779 ; 0.057]$} & {$[-1.15 ; 0.157]$} & {$[-0.703 ; 0.356]$} \\
\hline \multirow[t]{2}{*}{$\begin{array}{l}\text { Abortion } \\
\text { (females) }\end{array}$} & 0.092 & $0.123^{* *}$ & $0.123^{* *}$ & n.a. \\
\hline & $(0.29)$ & {$[0.020 ; 0.226]$} & {$[0.020 ; 0.226]$} & \\
\hline \multirow[t]{2}{*}{ Drugs } & 0.368 & -0.042 & -0.048 & -0.038 \\
\hline & $(0.483)$ & {$[-0.137 ; 0.054]$} & {$[-0.174 ; 0.077]$} & {$[-0.184 ; 0.107]$} \\
\hline \multirow[t]{2}{*}{ Alcohol } & 0.230 & 0.057 & 0.02 & 0.077 \\
\hline & $(0.421)$ & {$[-0.034 ; 0.148]$} & {$[-0.082 ; 0.121]$} & {$[-0.068 ; 0.222]$} \\
\hline
\end{tabular}

Notes: Treatment refers to the set of students that were assigned to the night shift by the lottery assignment. Control refers to the set of students that were assigned to the morning or afternoon shift by the lottery assignment. $E$ (Treatment)-E(Control) is the difference in means between the treatment and the control groups. Not surveyed is a dummy variable that takes value one if the student is in the 2013 cohort and did not answer the questionnaire. High School at Night is a variable indicating the percent of academic years the student attended the night shift. Primary school full time, morning, or afternoon are three dummy variables that take value one if the student attended the primary school full time, in the morning shift, or in the afternoon shift, respectively. Primary school public is a dummy variable that takes value one if the student attended the primary school at a public institution. Birth year is the year the student was born. Parents have higher education is a dummy variable that takes value one if at least one of the student's parents went to college. Female is a dummy variable that takes value one if the student is a female. Initiated is a dummy variable that takes value one if the student reports having ever had sex and is measured on the 2013 cohort sample, Age at sexual initiation is a count variable indicating the age at which the person had their first intercourse experience and is measured for the 1983-2009 cohorts. Abortion is a dummy variable that takes value one if the student reports having got an abortion and has been measured on the subsample of females. Drugs is a dummy that takes value one if the student reports that in a typical week (s)he consumes marijuana, cocaine, other hallucinogenic substances, or smokes. Alcohol is a dummy that takes value one if the student reports that in a typical week (s)he consumes alcoholic drinks, like beer, wine, white spirits, and bitters. Parental supervision is the proportion of the time the student is not at school in which at least one of his or her parents is not at work. Nightlife is the number of nights per week the students reports going out for recreation. Family dinners is the number nights per week the student reports having dinner with their family. Friends are older is the proportion of friends that are older than the student. Friends use substances is the proportion of friends of the student consume illegal substances. Works is a dummy that takes value one if the student reports having a job. Joint F-test $p$-value reports the $p$-value of the test of joint 
significance of pre-treatment characteristics to explain the lottery assignment of high school shift. The last three columns of the table report the results of a test of differences in means by lottery status. Bootstrapped $90 \%$ confidence intervals are shown in square brackets. The number of observations in the main survey is 263 except for Primary school shift indicators (262), abortion (98), drugs (257), alcohol (258), Nightlife (246), Family dinners (246), Friends are older (260), and Works (249). The number of observations in the pilot survey is 300 except for Primary school shift indicators (298), Primary school public (299), Age at sex initiation (264), abortion (163), drugs (296), and alcohol (296). ${ }^{* * *}$ Variable significant at the $1 \%$ level. ${ }^{* *}$ Variable significant at the $5 \%$ level. ${ }^{*}$ Variable significant at the $10 \%$ level.

Table 3 First Stage

\begin{tabular}{|l|c|c|c|c|}
\hline & \multicolumn{3}{l|}{ Main survey: 2013 cohort } & \multicolumn{2}{l|}{ Pilot survey: 1983-2009 cohorts } \\
\hline & High School at Night & $(3)$ & $(4)$ \\
\hline & $(1)$ & $(2)$ & $0.679^{* * *}$ & $0.666^{* * *}$ \\
\hline $\begin{array}{l}\text { Randomized into } \\
\text { the Night }\end{array}$ & $0.902^{* * *}$ & $0.903^{* * *}$ & & {$[0.587 ; 0.744]$} \\
\hline & {$[0.855 ; 0.950]$} & {$[0.856 ; 0.950]$} & {$[0.606 ; 0.752]$} & 297 \\
\hline Observations & 263 & 261 & 299 & \\
\hline
\end{tabular}

Notes: The dependent variable, High School at Night, is the percent of academic years the student attended the evening shift. Randomized into the Night is a dummy variable that takes value one if the student was assigned to the night shift thorough the lottery. Regressions in columns (2) and (4) include additional covariates. Covariates are Primary school full time, morning, or afternoon (three dummy variables that take value one if the student attended the primary school full time, in the morning shift, or in the afternoon shift, respectively); Primary school public (a dummy variable that takes value one if the student attended the primary school at a public institution); Birth year (the year the student was born); Parents have higher education (a dummy variable that takes value one if at least one of the student's parents went to college), and Female. Bootstrapped $90 \%$ confidence intervals are shown in square brackets. ${ }^{* * *}$ Variable significant at the $1 \%$ level.

Table 4 High school at night and risky behavior

\begin{tabular}{|c|c|c|c|c|c|c|}
\hline & \multicolumn{6}{|c|}{ Panel A: Main survey, 2013 cohort } \\
\hline & \multicolumn{4}{|c|}{ Females } & \multirow{2}{*}{\multicolumn{2}{|c|}{$\begin{array}{l}\text { Males } \\
\text { Initiated }\end{array}$}} \\
\hline & \multicolumn{2}{|l|}{ Initiated } & \multicolumn{2}{|l|}{ Abortion } & & \\
\hline & $(1)$ & (2) & (3) & (4) & (5) & (6) \\
\hline $\begin{array}{l}\text { Randomize } \\
\text { d into the } \\
\text { Night }\end{array}$ & $0.200^{*}$ & & $0.076^{*}$ & & $-0.158^{* *}$ & \\
\hline & $\begin{array}{c}{[0.010 ; 0.39} \\
0]\end{array}$ & & $\begin{array}{c}{[0.005 ; 0.14} \\
7]\end{array}$ & & $\begin{array}{c}-0.295 ;- \\
0.022] \\
\end{array}$ & \\
\hline $\begin{array}{l}\text { High School } \\
\text { at Night }\end{array}$ & & $0.213^{*}$ & & $0.081^{*}$ & & $-0.179^{* *}$ \\
\hline
\end{tabular}




\begin{tabular}{|c|c|c|c|c|c|c|}
\hline & & $\begin{array}{c}{[0.004 ; 0.42} \\
3]\end{array}$ & & $\begin{array}{c}{[0.005 ; 0.15} \\
7]\end{array}$ & & $\begin{array}{c}-0.333 ;- \\
0.026]\end{array}$ \\
\hline $\begin{array}{l}\text { Control } \\
\text { Group } \\
\text { Mean }\end{array}$ & \multicolumn{2}{|l|}{0.521} & \multicolumn{2}{|l|}{0} & \multicolumn{2}{|l|}{0.460} \\
\hline \multirow[t]{5}{*}{$\begin{array}{l}\text { Observation } \\
\mathrm{s}\end{array}$} & 99 & 99 & 98 & 98 & 164 & 162 \\
\hline & \multicolumn{6}{|c|}{ Panel B: Pilot survey, 1983-2009 cohorts } \\
\hline & \multicolumn{4}{|c|}{ Females } & \multicolumn{2}{|l|}{ Males } \\
\hline & \multicolumn{2}{|c|}{ Age at sex initiation } & \multicolumn{2}{|l|}{ Abortion } & \multicolumn{2}{|c|}{ Age at sex initiation } \\
\hline & $(7)$ & (8) & (9) & (10) & $(11)$ & $(12)$ \\
\hline \multirow{2}{*}{$\begin{array}{l}\text { Randomize } \\
d \text { into the } \\
\text { Night }\end{array}$} & $-0.773^{*}$ & & $0.142^{* *}$ & & 0.065 & \\
\hline & $\begin{array}{c}{[-1.529 ;-} \\
0.017]\end{array}$ & & $\begin{array}{c}{[0.048 ; 0.23} \\
6]\end{array}$ & & $\begin{array}{c}{[-} \\
0.608 ; 0.738 \\
]\end{array}$ & \\
\hline \multirow[t]{2}{*}{$\begin{array}{l}\text { High School } \\
\text { at Night }\end{array}$} & & $-1.019^{*}$ & & $0.202^{* *}$ & & 0.097 \\
\hline & & $\begin{array}{c}-1.97 ;- \\
0.069]\end{array}$ & & $\begin{array}{c}0.064 ; 0.34 \\
1]\end{array}$ & & $\begin{array}{c}- \\
0.887 ; 1.08]\end{array}$ \\
\hline $\begin{array}{l}\text { Control } \\
\text { Group } \\
\text { Mean }\end{array}$ & \multicolumn{2}{|l|}{17.776} & \multicolumn{2}{|l|}{0.054} & \multicolumn{2}{|l|}{17.197} \\
\hline $\begin{array}{l}\text { Observation } \\
s\end{array}$ & 141 & 141 & 163 & 163 & 122 & 122 \\
\hline
\end{tabular}

Notes: High School at Night is the percent of academic years the student attended the evening shift. Randomized into the Night is a dummy variable that takes value one if the student was assigned to the night shift thorough the lottery. The dependent variables are Initiated (a dummy variable that takes value one if the student reports having ever had sex and is measured on the 2013 cohort sample) in columns (1), (2), (5), and (6), Age at sex initiation (a count variable indicating the age at which the person had their first intercourse experience and is measured for the 1983-2009 cohorts) in columns (7), (8), (11), and (12), and Abortion (a dummy variable that takes value one if the student reports having got an abortion and that has been measured on the subsample of females) in columns (3), (4), (9), and (10). In columns (2), (4), (6), (8), (10), and (12) we instrument High School at Night with Randomized into the Night. All specifications include covariates. Covariates are Primary school full time, morning, or afternoon (three dummy variables that take value one if the student attended the primary school full time, in the morning shift, or in the afternoon shift, respectively); Primary school public (a dummy variable that takes value one if the student attended the primary school at a public institution); Birth year (the year the student was born); and Parents have higher education (a dummy variable that takes value one if at least one of the student's parents went to college). All regressions in panel B include cohort fixed effects. Bootstrapped $90 \%$ confidence 
intervals are shown in square brackets. ${ }^{* *}$ Variable significant at the $5 \%$ level. ${ }^{*}$ Variable significant at the $10 \%$ level.

Table 5 Mechanisms I: Parental supervision

\begin{tabular}{|c|c|c|c|c|c|}
\hline \multirow{2}{*}{$\begin{array}{l}\text { Dependent } \\
\text { variable: }\end{array}$} & \multicolumn{3}{|l|}{ Females } & \multicolumn{2}{|l|}{ Males } \\
\hline & Initiated & Abortion & Supervision & Initiated & Supervision \\
\hline & $(1)$ & $(2)$ & (3) & (4) & (5) \\
\hline \multicolumn{6}{|c|}{ Panel A: High school at night and parental supervision } \\
\hline \multirow[t]{2}{*}{$\begin{array}{l}\text { Randomized } \\
\text { into the Night }\end{array}$} & & & $-0.365^{* * *}$ & & $-0.246^{* * *}$ \\
\hline & & & $\begin{array}{c}-0.500 ;- \\
0.231]\end{array}$ & & $\begin{array}{c}-0.343 ;- \\
0.149]\end{array}$ \\
\hline $\begin{array}{l}\text { Control Group } \\
\text { Mean }\end{array}$ & & & 0.671 & & 0.64 \\
\hline Observations & & & 99 & & 162 \\
\hline \multicolumn{6}{|c|}{ Panel B: Parental supervision and sexual risky behavior } \\
\hline \multirow[t]{2}{*}{$\begin{array}{l}\text { Randomized } \\
\text { into the } \\
\text { Night*Full } \\
\text { Supervision } \\
(\alpha)\end{array}$} & -0.277 & -0.094 & & $0.322^{*}$ & \\
\hline & {$[-0.922 ; 0.368]$} & {$[-0.218 ; 0.030]$} & & {$[0.028 ; 0.616]$} & \\
\hline \multirow{2}{*}{$\begin{array}{l}\text { Randomized } \\
\text { into the Night } \\
(\delta)\end{array}$} & 0.200 & 0.093 & & $-0.243^{* * *}$ & \\
\hline & {$[-0.007 ; 0.408]$} & {$[0 ; 0.186]$} & & $\begin{array}{c}{[-0.399 ;-} \\
0.088]\end{array}$ & \\
\hline \multirow[t]{2}{*}{$\begin{array}{l}\text { Full } \\
\text { Supervision } \\
(\eta)\end{array}$} & $-0.234^{*}$ & 0.004 & & -0.039 & \\
\hline & $\begin{array}{c}-0.437 ;- \\
0.032] \\
\end{array}$ & {$[-0.007 ; 0.016]$} & & {$[-0.226 ; 0.148]$} & \\
\hline \multicolumn{6}{|c|}{ Null hypothesis: $\alpha+\delta=0$} \\
\hline $\begin{array}{l}\text { P-value of F- } \\
\text { statistic }\end{array}$ & 0.763 & 0.957 & & 0.614 & \\
\hline Observations & 99 & 98 & & 162 & \\
\hline
\end{tabular}

Notes: Panel A presents the estimates of the impact of going to school at night on parental supervision that result from estimating the model Parental supervision ${ }_{i}=a+b$ Evening $_{i}+c^{\prime} X_{i}+\epsilon_{i}$.

Parental supervision is a dummy variable that takes value one if in the two shifts that the student is not at school at least one of his or her parents is not at work, Randomized into the Night is a dummy variable that takes value one if the student was assigned to the night shift thorough the lottery, and $X$ is a vector of covariates described below. Panel B presents the estimates of coefficients $\alpha, \delta$, and $\eta$ 
in the regression model RiskyBehavior ${ }_{i}=$

$B+\alpha$ Evening $_{i}{ }^{*}$ FullSupervision $_{i}+\delta$ Evening $_{i}+\eta$ FullSupervision $_{i}+\gamma X_{i}+\epsilon_{i}$. Initiated is a dummy variable that takes value one if the student reports having ever had sex. Abortion is a dummy variable that takes value one if the student reports having got an abortion and that has been measured on the subsample of females. Full supervision is a dummy variable that takes value one if in the two shifts that the student is not at school at least one of his or her parents is not at work. Randomized into the Night*Full Supervision is the interaction term between Full supervision and Randomized into the Night. All specifications include covariates. Covariates are Primary school full time, morning, or afternoon (three dummy variables that take value one if the student attended the primary school full time, in the morning shift, or in the afternoon shift, respectively); Primary school public (a dummy variable that takes value one if the student attended the primary school at a public institution); Birth year (the year the student was born); and Parents have higher education (a dummy variable that takes value one if at least one of the student's parents went to college). Bootstrapped $90 \%$ confidence intervals are shown in square brackets. ${ }^{* * *}$ Variable significant at the $1 \%$ level. ${ }^{*}$ Variable significant at the $10 \%$ level.

Table 6 Mechanisms II: family and social influences

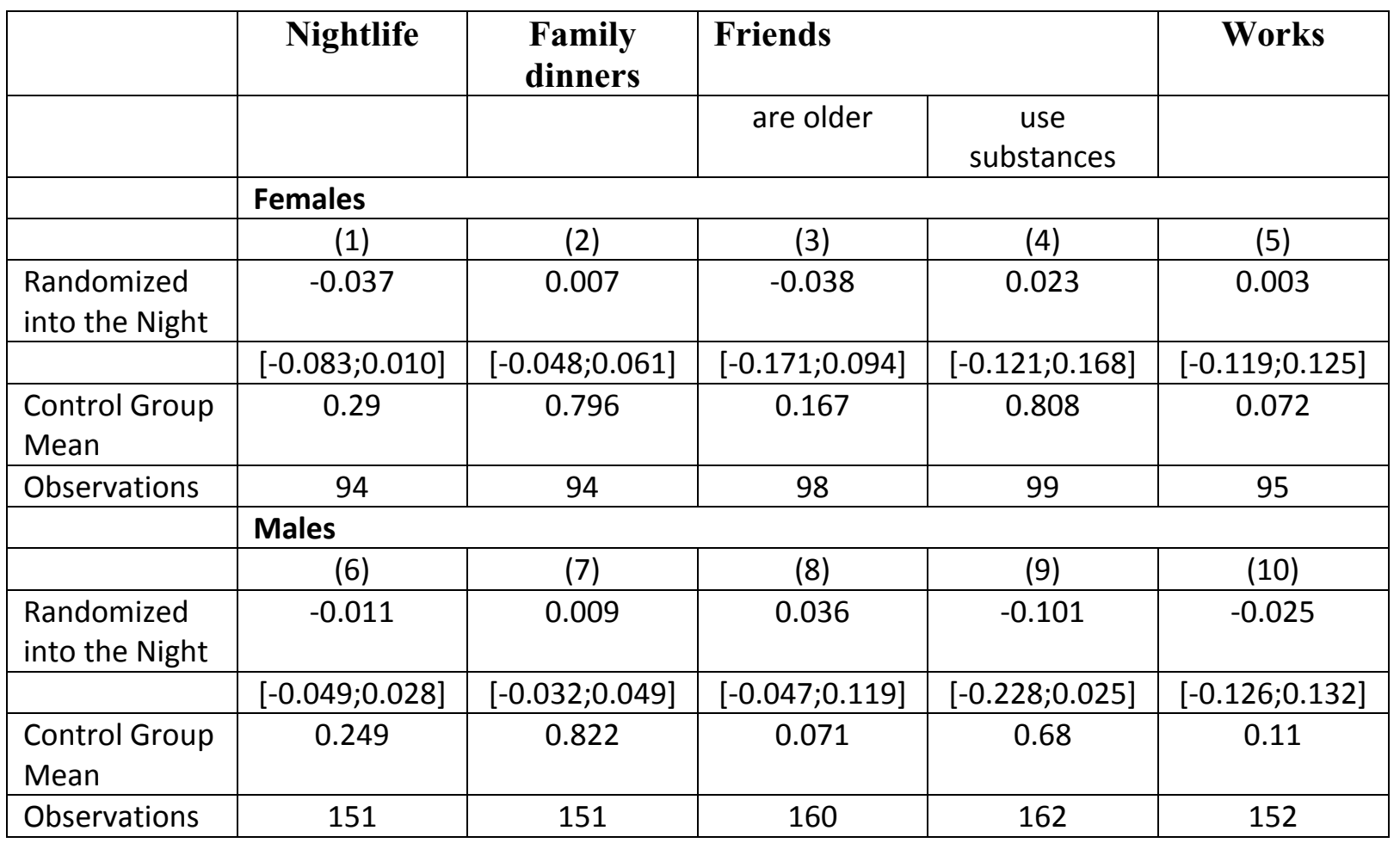

Notes: Nightlife is the number of nights per week the students reports going out for recreation. Family dinners is the number nights per week the student reports having dinner with their family. Friends are older is the proportion of friends that are older than the student. Friends use substances is the proportion of friends of the student consume illegal substances. Works is a dummy that takes 
value one if the student reports having a job. Randomized into the Night is a dummy variable that takes value one if the student was assigned to the night shift thorough the lottery. All effects shown are estimates of the Intention to Treat parameter. All specifications include covariates. Covariates are Primary school full time, morning, or afternoon (three dummy variables that take value one if the student attended the primary school full time, in the morning shift, or in the afternoon shift, respectively); Primary school public (a dummy variable that takes value one if the student attended the primary school at a public institution); Birth year (the year the student was born); and Parents have higher education (a dummy variable that takes value one if at least one of the student's parents went to college). Bootstrapped $90 \%$ confidence intervals are shown in square brackets.

Table 7 Mechanisms III: classroom peer effects

\begin{tabular}{|c|c|c|}
\hline & $\begin{array}{c}\mathrm{E} \text { (Shift by lottery)-E(Shift by } \\
\text { choice) }\end{array}$ & $90 \%$ Bootstrapped CI \\
\hline \multicolumn{3}{|l|}{ Pre-treatment characteristics: } \\
\hline Primary school full time & -0.005 & {$[-0.128 ; 0.118]$} \\
\hline Primary school morning & -0.046 & {$[-0.167 ; 0.076]$} \\
\hline Primary school afternoon & 0.051 & {$[-0.018 ; 0.120]$} \\
\hline Primary school public & 0.084 & {$[-0.041 ; 0.208]$} \\
\hline Birth year & -0.010 & {$[-0.257 ; 0.238]$} \\
\hline Parents have higher education & -0.063 & {$[-0.122 ;-0.005]$} \\
\hline Female & -0.106 & {$[-0.224 ; 0.013]$} \\
\hline
\end{tabular}

Notes: Shift by lottery refers to the sample of students that were assigned shift by lottery. The size of this sample is 319 students. Shift by choice refers to the sample of students that were allowed to choose shift. The size of this sample is 56 students. $E$ (Shift by lottery)-E(Shift by choice) is the difference in means between the two groups. The last column of the table reports the results of a test of differences in means by lottery status. Primary school full time, morning, or afternoon are three dummy variables that take value one if the student attended the primary school full time, in the morning shift, or in the afternoon shift, respectively. Primary school public is a dummy variable that takes value one if the student attended the primary school at a public institution. Birth year is the year the student was born. Parents have higher education is a dummy variable that takes value one if at least one of the student's parents went to college. Female is a dummy variable that takes value one if the student is a female. Bootstrapped $90 \%$ confidence intervals are shown in square brackets. 